\title{
Community-Based Dental Education and Dentists' Attitudes and Behavior Concerning Patients from Underserved Populations
}

\begin{abstract}
Ashok K. Rohra, B.A.; Wilhelm A. Piskorowski, D.D.S.; Marita R. Inglehart, Dr. phil. habil.
Abstract: The objectives of this study were to explore how dentists with well-structured vs. not well-structured communitybased dental education (CBDE) experiences differ in perceptions of their CBDE and its impact on their professional lives and in their professional attitudes and behavior related to treating patients from underserved populations. The relationships between CBDE evaluations and impact on the dentists' professional lives and professional attitudes and behavior were explored as well. Data were collected from 254 dentists who participated in CBDE before graduating from the University of Michigan School of Dentistry between 1970 and 2011. The results showed that the alumni with well-structured experiences rated the quality of their CBDE more positively and its impact on their professional lives as stronger than those with less well-structured experiences. They also had more positive attitudes concerning treating underserved patients and were more likely to treat underserved patients than their peers with less well-structured experiences. These dentists' perceptions of the quality of CBDE and impact on their professional lives correlated significantly with their attitudes and behavior concerning treating underserved patients. Their perceptions of the quality of their CBDE experiences and perceptions of benefits from these experiences were significantly related to their professional attitudes and behavior related to providing care for patients from underserved populations.
\end{abstract}

Mr. Rohra is a dental student, School of Dentistry, University of Michigan; Dr. Piskorowski is Assistant Dean for CommunityBased Dental Education, Patient Services and Clinical Associate Professor of Dentistry, Department of Cariology, Restorative Sciences, and Endodontics, School of Dentistry, University of Michigan; and Dr. Inglehart is Professor, Department of Periodontics and Oral Medicine, School of Dentistry and Adjunct Professor of Psychology, Department of Psychology, College of Literature, Science, and Arts, University of Michigan. Direct correspondence and requests for reprints to Dr. Marita R. Inglehart, Department of Periodontics and Oral Medicine, School of Dentistry, University of Michigan, 1011 North University Ave., Ann Arbor, MI 48109-1078; 734-763-8073; mri@umich.edu.

Keywords: community-based dental education, community service, service-learning, underserved patients, Medicaid, patients with special health care needs

Submitted for publication 6/16/12; accepted 2/12/13

$\mathrm{T}$ The U.S. surgeon general's report on oral health from 2000 focused attention on the fact that certain patient groups in the United States have disproportionate amounts of oral disease and face severe challenges with accessing oral health care services. ${ }^{1}$ These patient groups include patients from socioeconomically disadvantaged and/or minority groups and patients with special health care needs. For example, research has shown that socioeconomically disadvantaged U.S. citizens who are covered by Medicaid face challenges when trying to access oral health care services ${ }^{2}$ and that patients from minority groups are underserved in comparison to patients from European American groups. ${ }^{3}$ Concerning dental care services for patients with special health care needs, research has found that many general dentists $^{4}$ as well as dental specialists ${ }^{5,6}$ did not want to provide services for these patients. This situation needs attention because the numbers of patients in these particular segments of the U.S. population are increasing, ${ }^{7-9}$ making it crucial to ensure that future dental care providers will provide the much needed care for patients from these underserved groups.
Research in medical education has found that while increased general experiences with socioeconomically disadvantaged patients may not improve future physicians' attitudes and behavioral intentions concerning treating these patients, appropriately developed service-learning experiences may engage these students in a way that can lead to improved considerations of caring for these underserved patients. ${ }^{10}$ Concerning increasing health care services for underserved patients from minority groups, research in medical education has stressed the importance of including cultural competency training in medical school curricula ${ }^{11}$ and even in continuing education courses. ${ }^{12}$ A review article concerning the relationship between medical education experiences and health care students and professionals' attitudes towards patients with physical disabilities showed that increased interactions with these patients were related to more positive attitudes. ${ }^{13}$

Research has also shown that dental education in general can play an important role in improving future providers' attitudes towards providing care for underserved patients as well as their actual pro- 
fessional behavior. ${ }^{4-6,14,15}$ Personal and educational experiences with patients from these groups affected dental students' professional attitudes and their comfort level when interacting with these patients. ${ }^{16}$ While classroom-based as well as clinic-based dental education clearly needs to address providing care for underserved patients, dental education in community settings offers unique and rich opportunities for dental students to interact with patients from underserved populations and gain expertise in this context. ${ }^{17}$ In an overview of the history, current status, and future of community-based dental education (CBDE), Formicola and Bailit described how CBDE was first introduced in the late 1970s in the United States when federal grants were offered as incentives to dental schools to develop these programs. ${ }^{18}$ However, once these grants expired, most of these efforts came to a halt. During the past decade, dental schools began to embrace the benefits of CBDE again and have begun to develop well-designed programs. This development may be partly due to the realization that dental school outreach programs to underserved populations could contribute to reducing oral health disparities and to increasing access to care for these patients. ${ }^{18}$

Prior research has analyzed whether CBDE is able to contribute to this goal and whether it has positive long-term effects on the participants' willingness to treat underserved patients. ${ }^{19}$ The outcomes of these studies are inconsistent. For example, Piskorowski et al. found that the length of students' CBDE experience increased the likelihood that they would be interested in practice locations in which they would be more likely to treat underserved patients. ${ }^{19}$ The importance of the length of the program was also stressed in a study by Thind et al., who showed that the amount of time spent in rotations was a significant predictor of students' perceived ability to treat patients from underserved populations. ${ }^{20}$

Other authors also provided evidence for the positive effects of CBDE on graduates' awareness of the need to provide more dental care for underserved patients ${ }^{21}$ and their willingness to treat patients from underserved populations. ${ }^{22}$ In addition, having been involved in treating patients from underserved groups increased the likelihood to continue to provide care for these patient groups. ${ }^{23}$ Conflicting evidence, however, was provided by DeCastro et al., who showed that participation in a CBDE program did not affect alumni's attitudes towards providing care for underserved patients nor their willingness to accept patients on Medicaid. ${ }^{24}$
In consideration of these contradictory findings, we wanted to explore whether the quality of the CBDE - specifically, the degree to which a CBDE program is structured and well developed-affects participants' future professional attitudes and behavior concerning underserved patients. Our first aim in this study was therefore to assess whether alumni of one dental school who had participated in a less well-structured CBDE program differed in their evaluations of these experiences as well as in their assessments of the impact of these CBDE experiences on their professional lives from alumni who had participated in a well-structured program. Our second aim then focused on exploring the differences in professional attitudes and behavior concerning care for underserved patients between the participants in less well-structured vs. well-structured programs. Given that improvements in the programs as well as dental care in community-based offices might have developed over time, the relationships between these dentists' perceptions of their community-based educational experiences and evaluations of the impact on their professional lives and professional attitudes and behavior concerning treatment for underserved patients were explored as well. Our third aim was to assess whether these dental school alumni's evaluations of their CBDE and their perceptions of its impact on their professional lives were related to their actual professional attitudes and behavior concerning treating underserved patients.

\section{Methods}

This study was approved by the Institutional Review Board for the Behavioral and Health Sciences at the University of Michigan. An a priori power analysis with the program package $G^{*}$ Power 3.1.2 (www.psycho.uni-duesseldorf.de/abteilungen/ aap/gpower3) was conducted to compute the needed sample size given alpha $=0.05$, the power $=0.95$, and a medium effect size of 0.3 when using correlational analyses to test whether there were significant relationships between the evaluations of the CBDE and the respondents' professional attitudes and behavior. This analysis showed that 111 respondents would be needed. Data were collected from 254 alumni of the University of Michigan School of Dentistry. Emails were sent to 1,209 alumni who graduated in 1970, 1975, 1980, 1985, 1990, 1995, and 1998 and between 2000 and 2010. A total of 152 emails were returned due to incorrect email addresses, resulting in 1,057 delivered emails. 
CBDE/service-learning experiences were introduced into the dental curriculum at the University of Michigan School of Dentistry around 1970. These early experiences consisted of outreach programs to county health departments or special dental clinics such as clinics for migrant farm workers or clinics for patients with special health care needs. However, starting in 2001, CBDE at the school became much more structured. First, the students participated for a certain number of weeks in specifically chosen clinic sites that they were assigned to for an increasing number of weeklong rotations (2001-04: one to two weeks; 2005-07: three to four weeks; 2008: five weeks; 2009-11: eight weeks) during their senior year. ${ }^{19} \mathrm{~A}$ second change over time was that each site had to develop an orientation program to its rotation for the students to ensure that the students were clearly informed about the expectations they faced. These orientation programs improved over time based on the students' experiences and input. Third, increased effort was placed over the years on training and calibrating the supervising dentists in these sites. They became adjunct faculty members at the dental school and participated in regular retreats and education programs. A fourth characteristic of the program was that the supervising dentists received access to the dental school clinic manuals and infection control guidelines and were more recently even trained to evaluate the performance of students for their required test cases in cariology. Fifth, a rigorous feedback system was gradually implemented over the years. This feedback system requires each student to report back about his or her experiences at each site in three different evaluation forms and a reflective essay. In addition, the supervising clinicians provide detailed evaluations about each student.

With all these changes, there are significant differences in the way dental students were educated in community settings before 2001 and in 2001-11. Before 2001, the situation was relatively unstructured and could be described as providing students with service-learning experiences. Since 2001, however, actual CBDE has taken place. The responses of the alumni who graduated before 2001 will therefore be compared with the responses of the alumni who graduated between 2001 and 2011. In addition, the CBDE has been on a course of improvement over time. The relationships between the quality of these experiences and the alumni's attitudes and behavior will therefore be explored as well.

Email addresses for the alumni were obtained from the alumni office of the University of Michigan
School of Dentistry. The percentages of alumni for whom the office had email addresses ranged from the lowest percentage of 56 percent for the 2008 graduating class to 95 percent for the 2009 graduating class. On June 16 and June 17, 2011, recruitment emails were sent to all 1,209 alumni for whom email addresses were available. After 152 emails were returned due to incorrect addresses, the email list was corrected, and a first follow-up email was sent to the 1,057 remaining addresses on June 30 and July 1, 2011. Both recruitment emails informed the recipients about the study and asked them to volunteer and respond anonymously to a web-based survey to which they could connect with a web-link provided in the email.

The survey was provided on the UM Lessons website of the University of Michigan. This website is maintained by the university's Information Technology Division and allows university members to conduct surveys. The survey consisted of four parts. Part 1 asked respondents to provide background information such as the year in which they graduated from dental school. Part 2 focused on assessing their perceptions of their CBDE experiences, with six Likert-type questions about respondents' evaluation of their experiences with this type of education in general and six questions exploring the degree to which respondents believed these experiences had affected their professional lives related to providing care for underserved patients (see Table 1 for wording of the statements). Responses were given on five-point answer scales from 1=disagree strongly to $5=$ agree strongly. These same questions had been used throughout the program by the students to evaluate their experiences and to describe the degree to which these experiences were likely to affect their professional lives. ${ }^{19,25} \mathrm{~A}$ factor analysis (Extraction Method: Principal Component; Rotation Method: Varimax Rotation) was conducted to investigate whether these twelve items loaded as predicted on two factors. The assumed factor structure was confirmed. The reliability of these two scales was determined to be sufficient. The Cronbach alpha value for the six-item scale "Evaluation of community-based education" was 0.88 , and the Cronbach alpha value for the six-item scale "Impact on professional life" was 0.88 as well. The two indices "Evaluation of community-based education" and "Impact on professional life" were therefore computed by averaging the responses to the respective six items.

Part 3 consisted of five Likert-type questions that assessed the dentists' attitudes towards provid- 
Table 1. Respondents' evaluations of their community-based education experience and its impact on their professional lives

\begin{tabular}{|c|c|c|c|c|}
\hline Statement & $\begin{array}{l}1=\text { disagree } \\
\text { strongly and } \\
2=\text { disagree }\end{array}$ & $3=$ neutral & $\begin{array}{c}\text { 4=agree } \\
\text { and 5=agree } \\
\text { strongly }\end{array}$ & Mean/SD \\
\hline $\begin{array}{l}\text { a. I preferred treating patients in the outreach clinics to treating patients } \\
\text { in the dental school clinics. }\end{array}$ & $13 \%$ & $35 \%$ & $52 \%$ & $3.56 / 1.012$ \\
\hline $\begin{array}{l}\text { b. The faculty assistance in the community clinics was effective and } \\
\text { available. }\end{array}$ & $8 \%$ & $20 \%$ & $72 \%$ & $3.78 / 0.893$ \\
\hline c. I improved my clinical skills through the community-based education. & $6 \%$ & $14 \%$ & $80 \%$ & $4.10 / 0.905$ \\
\hline $\begin{array}{l}\text { d. I was exposed to different techniques and materials in the community } \\
\text { clinics compared to the dental school clinics. }\end{array}$ & $9 \%$ & $17 \%$ & $74 \%$ & $3.88 / 0.962$ \\
\hline $\begin{array}{l}\text { e. I deepened my respect for people from backgrounds other than my own } \\
\text { while working in a community dental clinic. }\end{array}$ & $8 \%$ & $34 \%$ & $59 \%$ & $3.69 / 0.877$ \\
\hline $\begin{array}{l}\text { f. The outreach experience was a valuable part of my education at the } \\
\text { School of Dentistry. }\end{array}$ & $4 \%$ & $9 \%$ & $87 \%$ & $4.34 / 0.841$ \\
\hline Index: Evaluation of community-based education ${ }^{a}$ & $\begin{array}{l}\text { Range from } \\
1.33\end{array}$ & & $\begin{array}{l}\text { To } \\
5.00\end{array}$ & $3.89 / 0.730$ \\
\hline $\begin{array}{l}\text { g. Because of my outreach experience during my dental education, I treat } \\
\text { a more diverse patient population now. }\end{array}$ & $30 \%$ & $42 \%$ & $28 \%$ & $3.07 / 1.073$ \\
\hline $\begin{array}{l}\text { h. Because of my outreach experience during my dental education, } \\
\text { I work with more underserved patients now. }\end{array}$ & $36 \%$ & $37 \%$ & $27 \%$ & $3.00 / 1.088$ \\
\hline $\begin{array}{l}\text { My outreach experiences prepared me well to treat patients: } \\
\text { i. with special needs. }\end{array}$ & $33 \%$ & $38 \%$ & $27 \%$ & $2.98 / 0.953$ \\
\hline j. on Medicaid. & $27 \%$ & $35 \%$ & $39 \%$ & $3.17 / 1.058$ \\
\hline k. as pro bono cases. & $30 \%$ & $48 \%$ & $22 \%$ & $2.92 / 0.949$ \\
\hline I. from different ethnic/racial groups. & $17 \%$ & $37 \%$ & $45 \%$ & $3.36 / 0.998$ \\
\hline Index: Impact on professional life ${ }^{b}$ & $\begin{array}{l}\text { Range from } \\
\quad 1.00\end{array}$ & & $\begin{array}{c}\text { To } \\
5.00\end{array}$ & 3.088/0.817 \\
\hline
\end{tabular}

ing care for underserved patients (see Table 2 for the wording of these questions). These questions had been used in earlier research by Brown and Inglehart ${ }^{5}$ and Garfinkle et al. ${ }^{6}$ This research showed that these items have good construct validity and reliability. The answer scale was identical to the scale used in Part 2 of the survey. Part 4 included five questions that asked respondents to estimate the percentages of their patients whose treatment was covered by Medicaid or who were treated as pro bono patients, who had special health care needs or developmental disabilities, or who came from disadvantaged backgrounds. In addition, a Likert-type question was added to this section that inquired about agreement with the statement "My practice includes patients from all ethnic/ racial backgrounds" to assess the behavior related to providing care for patients from minority groups (see
Table 2 for the wording of these questions). These questions had also been used and validated in earlier studies. ${ }^{5,6}$ The web-based version of this survey was piloted with two faculty members in the School of Dentistry who suggested minor changes in wording.

The data were collected on the UM Lessons website and downloaded from this site into an Excel file. This file was imported into SPSS (Version 19), and all analyses were performed with this program package. Descriptive statistics (frequencies, percentages, means, standard deviations, and ranges) were computed to describe the responses. Cronbach alpha coefficients were computed to assess the reliability of the two CBDE-related scales. Contingency coefficients were computed to determine the relationship between categorical variables, and Spearman's rho correlation coefficients were used to determine the 
Table 2. Respondents' attitudes and behavior related to treating patients from underserved populations

$\begin{array}{cc}1=\text { disagree } & 4=\text { agree } \\ \text { strongly and } & \text { and 5=agree }\end{array}$

Mean/SD

Attitude

I am confident treating patients with special needs.

$\begin{array}{llll}12 \% & 26 \% & 62 \% & 3.66 / 0.913 \\ 15 \% & 26 \% & 60 \% & 3.62 / 0.967 \\ 1 \% & 11 \% & 88 \% & 4.28 / 0.700 \\ 2 \% & 13 \% & 86 \% & 4.26 / 0.740 \\ 42 \% & 31 \% & 27 \% & 2.75 / 1.208 \\ 52 \% & 31 \% & 18 \% & 2.47 / 1.134 \\ 13 \% & 41 \% & 48 \% & 3.40 / 0.889 \\ 13 \% & 41 \% & 46 \% & 3.39 / 0.881 \\ 15 \% & 37 \% & 48 \% & 3.40 / 0.866 \\ 17 \% & 39 \% & 44 \% & 3.62 / 0.967\end{array}$

I like to treat patients with special health care needs.

$\begin{array}{cccc}6 \% & 2 \% & 91 \% & 4.32 / 0.869 \\ 7 \% & 3 \% & 90 \% & 4.30 / 0.884 \\ \text { Mean } & \text { SD } & \text { Minimum } & \text { Maximum } \\ 42 \% & 36.433 & 0 & 100 \% \\ 28 \% & 32.049 & 0 & 100 \% \\ 14 \% & 20.888 & 1 \% & 100 \% \\ 10 \% & 15.012 & 1 \% & 100 \% \\ 6 \% & 6.834 & 0 & 35 \% \\ 4 \% & 4.820 & 0 & 30 \% \\ 5 \% & 13.803 & 0 & 100 \% \\ 3 \% & 7.942 & 0 & 80 \% \\ 34 \% & 35.492 & 0 & 100 \% \\ 23 \% & 27.548 & 0 & 100 \%\end{array}$

Behavior

My practice includes patients from all ethnic groups.

Percentages of patients treated:

Patients with Medicaid

Patients with special health care needs

Patients with developmental disabilities

Patients as pro bono

Disadvantaged patients

$23 \%$

27.548

$100 \%$

Note: The percentage/Mean/SD in the top row with each item is information about all respondents, and the percentage/Mean/SD in the bottom row with each item is information about those respondents who did not and never had worked professionally in a community dental clinic.

relationships between the variables with continuous response scales. A significance level of $\mathrm{p} \leq 0.01$ was assumed to account for the fact that numerous correlations were computed.

\section{Results}

Out of 1,057 delivered emails, there were 254 respondents ( 24.26 percent response rate). The 254 respondents were between twenty-five and seventy-two years of age (Mean=37.81 years) and had graduated between 1970 and 2010. The majority of the respondents were male (58 percent) and from a European American background (74 percent); 14 percent were Asian American, 8 percent were African
American, and 3 percent were Hispanic. Thirty-nine respondents currently worked in a community dental clinic (15 percent), and an additional eight dentists had previously worked in a community dental clinic for loan repayment reasons.

Table 1 provides an overview of these alumni's evaluations of their CBDE experiences and the degree to which they perceived that these experiences had affected their professional lives. The majority evaluated their CBDE experiences as rather positive. For example, 87 percent agreed or strongly agreed with the statement that the outreach experience had been a valuable part of their education at the School of Dentistry and 80 percent that they had improved their clinical skills through the CBDE program. Concerning the impact of the CBDE on their professional 
activities related to providing care for underserved patients, 45 percent agreed or strongly agreed that their outreach experience had prepared them well to treat patients from different ethnic groups and 39 percent agreed or strongly agreed that the experience prepared them well to treat patients on Medicaid. However, fewer respondents agreed/strongly agreed that their CBDE had prepared them well to treat patients with special health care needs $(\mathrm{SHCN})$ or pro bono cases.

When considering the respondents' attitudes and behavior related to treating underserved patients, it is important to note that some alumni worked in community clinics that provide care for underserved patients. To consider this fact in the analyses, Table 2 provides an overview of these responses first for all respondents and then for only those respondents who were not employed in a community dental clinic. For example, while the average percentage of patients covered by Medicaid was 42 percent when the data from all respondents were analyzed, it dropped to 28 percent when only the data from the respondents who were not employed in community clinics were analyzed. This differentiated information is provided because considering the information for all dentists might overestimate how many dentists in non-community clinic settings treated underserved patients. However, a comparison of the attitudes of all dentists and dentists without professional experiences in community dental clinics showed that attitudes did not differ substantially for nearly all groups of patients. When the dentists with community dental clinic experiences were included, the attitudes towards patients on Medicaid were slightly more positive than when only the attitudes of dentists without such experiences were considered.

This pattern of findings was replicated for the responses concerning these alumni's actual professional behavior. Again, the percentages of patients on Medicaid and in addition the responses concerning providing care for disadvantaged patients were higher when the responses of all alumni were considered compared to the responses of the alumni without professional community clinic experiences. Overall, these results show that the attitudes ranged from being very negative to very positive, and the behaviors ranged from not at all providing care for patients in these underserved groups to providing only care for these patients. In addition, the results showed that while their attitudes and the professional behavior concerning patients from different ethnic/racial groups were quite accepting, their attitudes and pro- fessional behavior concerning socioeconomically disadvantaged patients were considerably less positive.

Tables 3 and 4 provide an overview of responses of alumni who graduated before 2001 and participated in an unstructured CBDE program vs. responses of alumni from 2001-11, who experienced well-structured CBDE. The comparisons of the program evaluations of alumni in less vs. wellstructured CBDE programs (Table 3) confirmed our expectation that the CBDE experiences of the first group of alumni were significantly less positive than the experiences of the younger cohorts and that the older cohorts reported a lower level of impact of these experiences on their professional lives.

Table 4 provides a comparison of these dentists' responses in the less vs. well-structured CBDE program concerning their attitudes and behavior related to treating underserved patients. Again, these responses were first analyzed by including data from all respondents in the two groups and then by considering only the responses of alumni who did not work in community dental clinics. The first set of comparisons with all respondents showed that the attitudes towards patients on Medicaid were better if the dentist had participated in well-structured educational programs (on a five-point scale from $1=$ disagree strongly to $5=$ agree strongly: 2.14 vs. 2.99 ; $\mathrm{p}<0.001$ ). However, the attitudes towards patients from different ethnic groups, patients with SHCN, and pro bono cases did not differ between the two groups of respondents. The same pattern of findings was repeated when only data from alumni who did not work in community clinics were analyzed. However, the attitudes were then slightly less positive.

Concerning behavior related to treating underserved patients, the alumni who had participated in well-structured programs treated more patients on Medicaid (52 percent vs. 16 percent; $p<0.001$ ), with developmental disabilities ( 6 percent vs. 3 percent; $\mathrm{p}<0.001$ ), and from disadvantaged backgrounds (42 percent vs. 14 percent; $p<0.001)$ than their peers with less well-structured experiences (Table 4). They were also more likely to agree that their practice included patients from all ethnic groups (4.38 vs. 4.11; $\mathrm{p}<0.05$ ). Again, this same pattern of results was found when the data from dentists not working in community clinics were analyzed. However, the percentages of patients treated were smaller in this case.

Table 5 provides an overview of the relationships between the respondents' perceptions of their community-based education and the impact of this education on their professional lives and attitudes to- 
Table 3. Respondents' evaluations of community-based educational experiences in well-structured vs. less well-structured programs

\begin{tabular}{|c|c|c|c|}
\hline Statement & $\begin{array}{c}\text { Less Well } \\
\text { Structured } \\
\quad N=76\end{array}$ & $\begin{array}{c}\text { Well } \\
\text { Structured } \\
N=178\end{array}$ & $\mathrm{p}$ \\
\hline $\begin{array}{l}\text { I preferred treating patients in the outreach clinics to treating patients in the } \\
\text { dental school clinics. }\end{array}$ & 3.11 & 3.72 & $<0.001$ \\
\hline The faculty assistance in the community clinics was effective and available. & 3.37 & 3.94 & $<0.001$ \\
\hline I improved my clinical skills through the community-based education. & 3.63 & 4.28 & $<0.001$ \\
\hline $\begin{array}{l}\text { I was exposed to different techniques and materials in the community clinics } \\
\text { compared to the dental school clinics. }\end{array}$ & 3.45 & 4.05 & $<0.001$ \\
\hline $\begin{array}{l}\text { I deepened my respect for people from backgrounds other than my own while } \\
\text { working in a community dental clinic. }\end{array}$ & 3.56 & 3.75 & 0.134 \\
\hline The outreach experience was a valuable part of my education at the School of Dentistry. & 3.76 & 4.54 & $<0.001$ \\
\hline Index: Evaluation of community-based education & 3.48 & 4.04 & $<0.001$ \\
\hline $\begin{array}{l}\text { Because of my outreach experience during my dental education, I treat a more diverse } \\
\text { patient population now. }\end{array}$ & 2.75 & 3.18 & 0.004 \\
\hline $\begin{array}{l}\text { Because of my outreach experience during my dental education, I work with more } \\
\text { underserved patients now. }\end{array}$ & 2.63 & 3.14 & 0.001 \\
\hline $\begin{array}{l}\text { My outreach experiences prepared me well to treat patients: } \\
\text { with special needs. }\end{array}$ & 2.81 & 3.03 & 0.094 \\
\hline on Medicaid. & 2.44 & 3.45 & $<0.001$ \\
\hline as pro bono cases. & 2.66 & 3.02 & 0.007 \\
\hline from different ethnic/racial groups. & 2.92 & 3.51 & $<0.001$ \\
\hline Index: Impact on professional life & 2.67 & 3.23 & $<0.001$ \\
\hline
\end{tabular}

Table 4. Respondents' attitudes and behavior concerning patients from underserved groups for those with less wellstructured vs. well-structured community-based education experiences

\begin{tabular}{|c|c|c|c|c|}
\hline & \multicolumn{2}{|c|}{ All Respondents } & \multicolumn{2}{|c|}{$\begin{array}{c}\text { Respondents } \\
\text { Not in Community Clinics }\end{array}$} \\
\hline & $\begin{array}{c}\text { Less } \\
\text { Well Structured } \\
N=76\end{array}$ & $\begin{array}{l}\text { Well Structured } \\
\qquad N=178\end{array}$ & $\begin{array}{c}\text { Less } \\
\text { Well Structured } \\
N=72\end{array}$ & $\begin{array}{l}\text { Well Structured } \\
\qquad N=150\end{array}$ \\
\hline \multicolumn{5}{|l|}{ Attitude } \\
\hline I am confident treating patients with special needs. & 3.53 & 3.69 & 3.52 & 3.69 \\
\hline I like treating patients from different ethnic groups. & 4.24 & 4.30 & 4.24 & 4.30 \\
\hline I like to treat patients on Medicaid. & 2.14 & $2.99 * * *$ & 2.06 & $2.79 * * *$ \\
\hline I like to treat patients as pro bono cases. & 3.30 & 3.43 & 3.32 & 3.42 \\
\hline I like to treat patients with special needs. & 3.32 & 3.42 & 3.31 & 3.36 \\
\hline \multicolumn{5}{|l|}{ Behavior } \\
\hline$\%$ patients with private insurance & $64 \%$ & $56 \% *$ & $65 \%$ & $63 \%$ \\
\hline$\%$ patients with private pay & $27 \%$ & $21 \% *$ & $28 \%$ & $22 \% *$ \\
\hline$\%$ patients on Medicaid & $16 \%$ & $52 \% * * *$ & $12 \%$ & $39 \% * * *$ \\
\hline$\%$ patients with special health care needs & $11 \%$ & $14 \%$ & $11 \%$ & $10 \%$ \\
\hline$\%$ patients with developmental disabilities & $3 \%$ & $6 \% * * *$ & $3 \%$ & $5 \% *$ \\
\hline$\%$ patients pro bono & $3 \%$ & $6 \%$ & $3 \%$ & $4 \%$ \\
\hline$\%$ patients who are disadvantaged & $14 \%$ & $42 \% * * *$ & $14 \%$ & $30 \% * * *$ \\
\hline My practice includes patients from all ethnic groups. & 4.11 & $4.38^{*}$ & 4.10 & $4.39 *$ \\
\hline \multicolumn{5}{|l|}{${ }^{*} \mathrm{p} \leq 0.05 ; * * \mathrm{p} \leq 0.01 ; * * * \mathrm{p} \leq 0.001$} \\
\hline
\end{tabular}


Table 5. Spearman's rho correlation coefficients between respondents' evaluation of community-based education and impact on professional life and attitudes

\begin{tabular}{|c|c|c|c|c|c|c|}
\hline & \multicolumn{5}{|c|}{ I like to treat patients ${ }^{c}$} & \multirow{2}{*}{$\begin{array}{l}\text { Confident } \\
\text { Treating } \\
\text { SHCN } \\
\text { Patients }\end{array}$} \\
\hline & $\begin{array}{l}\text { Graduation } \\
\text { Year }\end{array}$ & $\begin{array}{l}\text { from } \\
\text { different } \\
\text { ethnicities }\end{array}$ & $\begin{array}{l}\text { on } \\
\text { Medicaid }\end{array}$ & $\begin{array}{l}\text { pro } \\
\text { bono } \\
\text { patients }\end{array}$ & $\begin{array}{l}\text { with } \\
\text { SHCN }\end{array}$ & \\
\hline Graduation year & - & -0.03 & $0.39 * * *$ & 0.10 & 0.10 & 0.04 \\
\hline $\begin{array}{l}\text { Evaluation of CBDE and of impact on professional life } \\
\text { a. I preferred treating patients in the outreach clinics } \\
\text { to treating patients in the dental school clinics. }\end{array}$ & $0.30^{* * *}$ & 0.04 & 0.12 & 0.06 & $0.14^{*}$ & $0.14^{*}$ \\
\hline $\begin{array}{l}\text { b. The faculty assistance in the community clinics was } \\
\text { effective and available. }\end{array}$ & $0.31^{* * *}$ & $0.13^{*}$ & $0.14^{*}$ & 0.05 & $0.20^{* *}$ & $0.16^{*}$ \\
\hline $\begin{array}{l}\text { c. I improved my clinical skills through the community } \\
\text { based education. }\end{array}$ & $0.33^{* * *}$ & $0.13^{*}$ & $0.18^{* *}$ & 0.10 & $0.29^{* * *}$ & $0.30^{* * *}$ \\
\hline $\begin{array}{l}\text { d. I was exposed to different techniques and materials } \\
\text { in the community clinics compared to the dental } \\
\text { school clinics. }\end{array}$ & $0.32^{* * *}$ & $0.17^{* *}$ & $0.13^{*}$ & 0.04 & $0.25^{* * *}$ & $0.24^{* * *}$ \\
\hline $\begin{array}{l}\text { e. I deepened my respect for people from backgrounds } \\
\text { other than my own while working in a community } \\
\text { dental clinic. }\end{array}$ & 0.12 & $0.26^{* * *}$ & $0.14 * *$ & $0.16^{*}$ & $0.30^{* * *}$ & $0.23^{* * *}$ \\
\hline $\begin{array}{l}\text { f. The outreach experience was a valuable part of my } \\
\text { education at the School of Dentistry. }\end{array}$ & $0.38^{* * *}$ & $0.17^{*}$ & $0.23 * * *$ & 0.09 & $0.26^{* * *}$ & $0.29 * * *$ \\
\hline $\begin{array}{l}\text { Index: Evaluation of community-based education }{ }^{\text {b }} \\
\text { (alpha }=0.88)\end{array}$ & $0.37^{* * *}$ & $0.20^{* *}$ & $0.20^{* * *}$ & 0.10 & $0.31^{* * *}$ & $0.29^{* * *}$ \\
\hline $\begin{array}{l}\text { g. Because of my outreach experience during my } \\
\text { dental education, I treat a more diverse patient } \\
\text { population now. }\end{array}$ & $0.20^{* *}$ & $0.14^{*}$ & $0.20^{*}$ & 0.01 & $0.22^{* * *}$ & $0.16^{*}$ \\
\hline $\begin{array}{l}\text { h. Because of my outreach experience during my } \\
\text { dental education, I work with more underserved } \\
\text { patients now. }\end{array}$ & $0.25^{* * *}$ & $0.13^{*}$ & $0.33^{* * *}$ & 0.03 & $0.26^{* * *}$ & $0.14^{*}$ \\
\hline My outreach experiences prepared me well to treat pati & ents & & & & & \\
\hline i. with special needs. & 0.12 & $0.19^{* *}$ & $0.17^{* *}$ & $0.18^{* *}$ & $0.35^{* * *}$ & $0.28^{* * *}$ \\
\hline j. on Medicaid. & $0.53^{* * *}$ & 0.08 & $0.43^{* * *}$ & $0.15^{*}$ & $0.21^{* * *}$ & $0.15^{*}$ \\
\hline k. as pro bono cases. & $0.18^{* *}$ & $0.15^{*}$ & 0.07 & $0.25^{* * *}$ & $0.16^{*}$ & 0.09 \\
\hline I. from different ethnic/racial groups. & $0.30^{* * *}$ & 0.11 & 0.10 & 0.07 & $0.17^{* *}$ & $0.16^{*}$ \\
\hline Index: Impact on professional life ${ }^{c}(a l p h a=0.88)$ & $0.38^{* * *}$ & $0.17^{* *}$ & $0.29 * * *$ & $0.13^{*}$ & $0.30^{* * *}$ & $0.21^{* * *}$ \\
\hline${ }^{*} \mathrm{p} \leq 0.05 ; * * \mathrm{p} \leq 0.01 ; * * * \mathrm{p} \leq 0.001$ & & & & & & \\
\hline $\begin{array}{l}\text { aAnswers were given on a scale from } 1=\text { disagree strongly } \\
\text { bThe index "Evaluation of community-based education" } \mathrm{w} \\
\text { "The index "Impact on professional life" was computed by }\end{array}$ & $\begin{array}{l}5=\text { agree str } \\
\text { s computed } \\
\text { averaging the }\end{array}$ & $\begin{array}{l}\text { y. } \\
\text { veraging } t \\
\text { swers to it }\end{array}$ & $\begin{array}{l}\text { nswers t } \\
\text { g to I. }\end{array}$ & $m s$ a to $f$. & & \\
\hline
\end{tabular}

wards treating underserved patients. As expected, the graduation year was significantly correlated with all but one of the educational indicators. In addition, the better the evaluations were, the more positive the respondents' attitudes were. These dentists' assessments of the impact of CBDE on their professional lives and their professional attitudes concerning providing care for underserved patients correlated as well.
Table 6 provides an overview of the relationships between the CBDE evaluations and actual professional behavior. While the graduation year had not been correlated with most of the respondents' attitudes, it was significantly correlated with all but the pro bono indicator of their professional behavior. The higher the graduation year (and the younger the respondent), the higher were the percentages of the 
dentist's patients on Medicaid or from disadvantaged backgrounds and the percentages of patients with SHCN and developmental disabilities.

The relationships between the perceptions of the CBDE and the respondents' professional behavior showed that the more positively they evaluated their CBDE overall (see Index "Evaluation of community-based education"), the higher were the percentages of patients with SHCN, patients with developmental disabilities, pro bono patients, and patients from disadvantaged backgrounds. In addition, the degree to which the alumni reported that their CBDE experiences had impacted their future professional lives, the higher were the percentages of patients covered by Medicaid, patients with SHCN and developmental disabilities, and patients from disadvantaged backgrounds.

\section{Discussion}

The current trend to increase the percentage of time that dental students spend in communitybased educational programs deserves attention for several reasons such as the financial consequences for the dental schools ${ }^{26}$ as well as considerations of the impact on the students' proficiency in their clinical work. This study focused on the consequences of CBDE on these future dentists' professional attitudes and behavior related to providing care for underserved patients. The study specifically explored whether participation in well-structured CBDE programs with their exposure to providing care for underserved patients will motivate students to include patients from underserved groups in their patient families.

An overview of the program evaluations showed that the alumni differed widely in how they evaluated their CBDE experiences and the impact of the CBDE on their professional lives (see Table 1). However, as predicted, the alumni with less wellstructured CBDE experiences had significantly less positive evaluations than the alumni who participated in the well-structured CBDE program between 2001 and 2011 (see Table 3). In addition, gradual improvements over time may have occurred as well. It is therefore not surprising that the respondents' age was correlated with their CBDE evaluations, with these experiences being more positive the younger the alumni were (see Table 5). These findings might also be related to changes in the funding for community dental clinics and especially the funding for dental care in, for example, Federally Qualified Health Centers.

An overview of these dentists' attitudes and behavior related to treating underserved patients showed that they differed widely from being quite negative and exclusive to being very positive and inclusive (see Table 2). This fact is not surprising because research has shown that personal experiences with underserved patients such as having been covered by Medicaid clearly affects one's attitudes and professional behavior. ${ }^{16}$ Dental students differ widely in their personal characteristics (such as in their families' socioeconomic situation and their ethnic/racial group), and these differences are likely to affect future behavior. ${ }^{3}$

When the attitudes of these alumni with less vs. well-structured CBDE experiences were compared, only one significant difference was found. Alumni in less well-structured programs were less positive about patients covered by Medicaid than alumni in well-structured programs. However, the two groups differed more widely in their actual behavior. The differences between these two groups concerning the percentages of patients on Medicaid (52 percent vs. 16 percent) and of patients from disadvantaged backgrounds ( 42 percent vs. 14 percent) are considerable. These differences were still quite considerable when only data from alumni not working in community clinics were analyzed (Medicaid: 12 percent vs. 39 percent; disadvantaged backgrounds: 14 percent vs. 30 percent).

In addition to comparing the responses of the alumni in these two groups, correlations between educational evaluations and attitudes concerning providing care for patients covered by Medicaid and behavior related to underserved patient care were also found to be significant. Specifically, Table 6 draws attention to the important fact that the better the alumni felt prepared to provide care for a specific patient group, the more likely they were to provide care for those patients. Given that Medicaid patients are clearly overrepresented in community clinics (which offer substantial opportunities for dental students to interact with these patients), the increase in the number of patients on Medicaid treated by younger alumni is not surprising.

While significant changes in the CBDE program at the University of Michigan School of Dentistry have occurred over time, it is clear that other factors play a role in this context as well. Such factors could be related to the current economic situation as well as to changes in the administration of the 
Table 6. Spearman's rho correlation coefficients between evaluations of educational experiences and impact on professional life and respondents' professional behavior

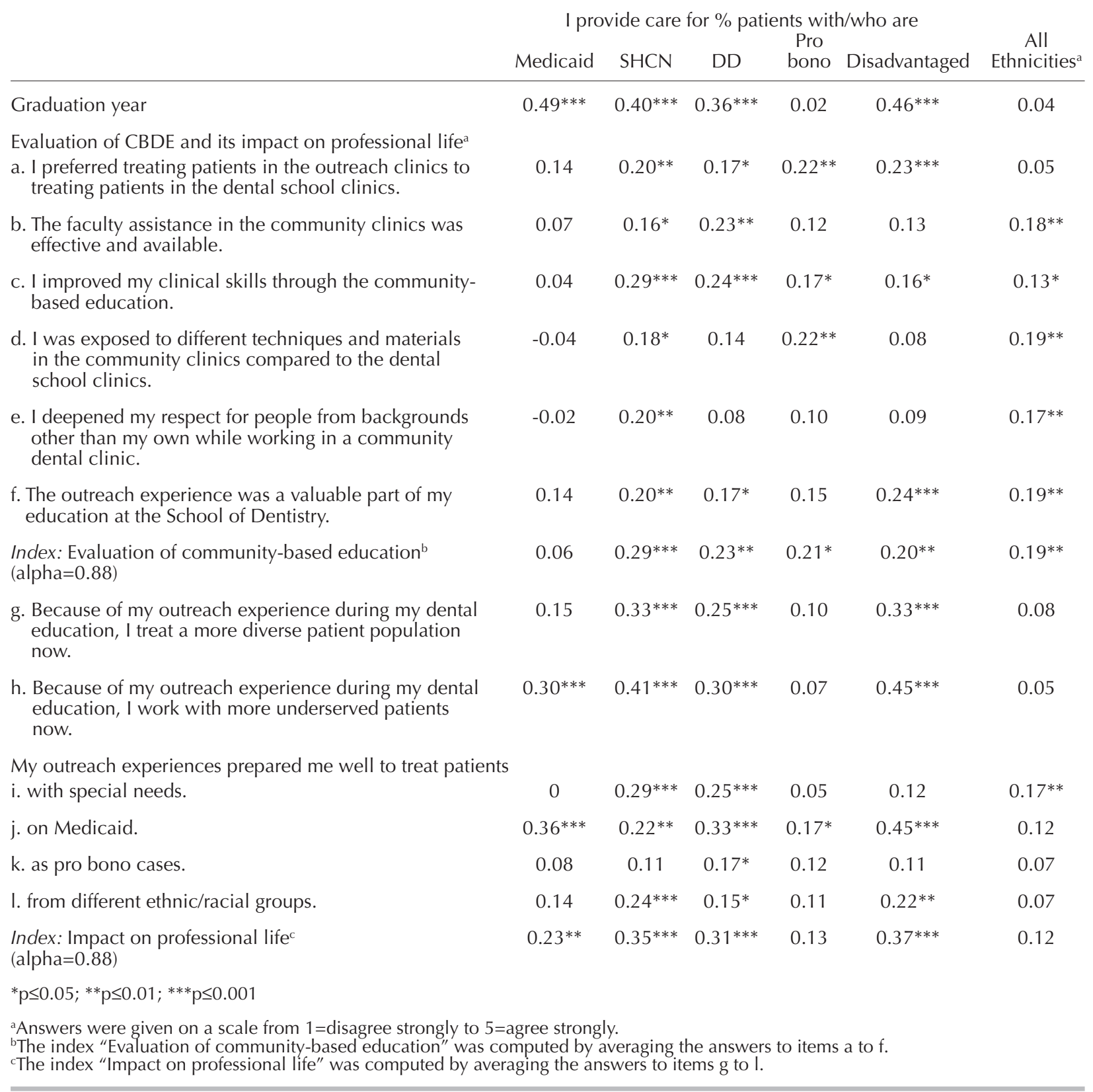

Medicaid program. For example, computer-based submission of claims reduces the turnaround time for reimbursement significantly. Another explanation for why younger graduation cohorts may be more likely to provide care for underserved patients could be that more women have been included in more recent cohorts compared to the oldest cohorts. ${ }^{27}$ Such demographic changes might affect practice characteristics. For example, previous research showed that female health care providers had more positive attitudes towards patients with special health care needs. ${ }^{13}$

It is noteworthy in this context that the one group of providers who are most likely to provide care for patients from minority groups and/or socioeconomically disadvantaged backgrounds-namely, providers from minority groups-were not only underrepresented among the respondents in this study but among dental students and dentists in the United 
States overall. As Woolfolk and Price showed in their review of dental student enrollment data over time, not much change has occurred concerning the enrollment of black and Hispanic dental students over the past decades. ${ }^{27}$ Based on the research published in the Sullivan report, ${ }^{3}$ increasing the number of these "missing persons in the health professions" could clearly contribute to reducing the access to dental care problem in the United States.

The findings of our study have clear implications for dental education and should be a call to action for dental educators. The fact that perceptions of the quality of CBDE were clearly correlated with the dentists' attitudes and especially their professional behavior related to providing care for underserved patients is important to note. Previous research showed that the quality of classroom-based and clinic-based education concerning treatment of patients from underserved groups was related to the future professional behavior of dental students. ${ }^{5-10}$ However, these findings point to the importance of well-structured CBDE in order to ensure that it will be related to positive outcomes concerning the treatment of underserved patients.

Considering potential limitations of this research, one question could be whether the quality of the data, especially the sample and the response rate, is sufficient to base wide-reaching conclusions on it. Considering the sample size, an a priori power analysis showed that the number of respondents included exceeded the number of respondents needed to test the most important hypothesis: whether there is a relationship between perceptions of the CBDE and the actual behavior related to providing care for underserved patients. In addition, the characteristics of the sample might pose a study limitation. For example, alumni who provide their email addresses to a dental school's development office might differ in their evaluations of their educational experiences from alumni who do not provide this information. However, the fact that the responses ranged from very negative to very positive evaluations of the CBDE allows exploring the hypotheses of interest herenamely, whether there were relationships between perceptions of CBDE experiences and professional attitudes and behavior.

A potential limitation is the response rate of 24.26 percent. However, Sheehan showed in 2006 that one major problem of web-based surveys is a low response rate and that the response rates to electronic surveys declined over the past years considerably. ${ }^{28}$ Most recently, Hardigan et al. compared the response rates to surveys that were mailed vs. electronically accessible for practicing dentists. ${ }^{29}$ They found that while electronic surveys were 2.68 times more costeffective than mailed surveys, the response rates were far better for mailed surveys ( 28 percent) than for web-based surveys (11 percent). Additionally, when given an option to complete a survey online or by mail, the dentists clearly preferred responding via postal mail (94 percent) versus online ( 6 percent). In considerations of the results of these two studies, the response rate to this web-based survey is acceptable.

However, this study had one clear limitation: the respondents all attended one dental school. This fact might shape the responses. In addition, it is unclear whether the respondents differed in any systematic way from nonrespondents. For example, respondents might have been more interested in the topic of this study than nonrespondents. Their attitudes and professional behavior might therefore be different from those of practicing dentists in the United States in general. The findings might therefore overestimate how positively alumni in general would evaluate their CBDE.

\section{Conclusions}

The findings from this study emphasize the importance of creating well-structured communitybased dental education programs. The more structured and developed the CBDE program at the University of Michigan School of Dentistry became over the years, the more positively the alumni perceived this program to be and the more they agreed that it had affected their professional lives. The more positively the alumni assessed their CBDE experiences, the better were their attitudes concerning providing care for patients covered by Medicaid and their behavior related to caring for underserved patients. While a number of factors will affect whether dentists provide care for underserved patients, dental educators should note that the quality of CBDE will shape future providers' professional attitudes and behaviors.

\section{Acknowledgments}

We want to thank the University of Michigan School of Dentistry for providing us with the email addresses of their alumni and the alumni who responded to this survey. We also want to thank Paula De Oliveira for her help with the data collection and the preparation of the data for analysis. 


\section{REFERENCES}

1. Oral health in America: a report of the surgeon general. Rockville, MD: U.S. Department of Health and Human Services, National Institute of Dental and Craniofacial Research, National Institutes of Health, 2000.

2. ADA Survey Center. Just the facts: Medicaid. ADA News 2009;40(11):1.

3. Missing persons: minorities in the health professions. A report of the Sullivan Commission on Diversity in the Healthcare Workforce. At: http://health-equity.pitt. edu/40/. Accessed: October 7, 2012.

4. Dao LP, Zwetchkenbaum S, Inglehart MR. General dentists and special needs patients: does dental education matter? J Dent Educ 2005;69(10):1107-15.

5. Brown BR, Inglehart MR. Orthodontists' and orthodontic residents' education in treating underserved patients: effects on professional attitudes and behavior. J Dent Educ 2009;73(5):550-62.

6. Garfinkle AJ, Richards PS, Inglehart MR. Providing care for underserved patients: periodontists' and periodontal residents' educational experiences, attitudes, and behaviors. J Periodontol 2010;81(11):1604-12.

7. Albino JEN, Inglehart MR, Tedesco LA. Dental education and changing oral health care needs: disparities and demands. J Dent Educ 2012;76(1):75-88.

8. Day JC, U.S. Census Bureau. National population projections. At: www.census.gov/population/www/pop-profile/ natproj.html. Accessed: May 24, 2012.

9. U.S. Census Bureau. American community survey/Puerto Rico community survey, 2006 subject definitions. At: www.census.gov/acs/www/Downloads/data_documentation/SubjectDefinitions/2006_ACSSubject Definitions. pdf. Accessed: May 24, 2012.

10. Wear D, Kuczewski MG. Perspective: medical students' perceptions of the poor - what impact can medical education have? Acad Med 2008;83(7):639-45.

11. Brach C, Fraser I. Can cultural competence reduce racial and ethnic health disparities? A review and conceptual model. Med Care Res Rev 2000;57(Suppl 1):181-217.

12. Like RC. Educating clinicians about cultural competence and disparities in health and health care. J Contin Educ Health Prof 2011;31(3):196-206.

13. Satchidanand N, Gunukula SK, Lam WY, et al. Attitudes of health care students and professionals toward patients with physical disability: a systematic review. Am J Phys Med Rehabil 2012;91:533-45.

14. Smith CS, Ester TV, Inglehart MR. Dental education and care for underserved patients: analysis of students' intentions and alumni behavior. J Dent Educ 2006;70(4):398408 .
15. Rich JP, Straffon L, Inglehart MR. General dentists and pediatric dental patients: the role of dental education. J Dent Educ 2006;70(12):1308-15.

16. Valentine A, Inglehart MR. Medicaid patients in dental school clinics: do personal and professional experiences matter? J Dent Educ 2011;75(9):1225-35.

17. Kuthy RA, Heller KE, Riniker KJ, et al. Students' opinions about treating vulnerable populations immediately after completing community-based clinical experiences. J Dent Educ 2007;71(5):646-54.

18. Formicola AJ, Bailit HL. Community-based dental education: history, current status, and future. J Dent Educ 2012;76(1):98-106.

19. Piskorowski WA, Stefanac SJ, Fitzgerald M, et al. Influence of community-based dental education on dental students' preparation and intent to treat underserved populations. J Dent Educ 2012;76(5):534-9.

20. Thind A, Atchison K, Anderson R. What determines positive student perceptions of extramural clinical rotations? An analysis using 2003 ADEA senior survey data. J Dent Educ 2005;69(3):355-62.

21. Strauss RP, Stein MB, Edwards J, Nies KC. The impact of community-based dental education on students. J Dent Educ 2010;74(10 Suppl):S42-55.

22. Davidson PL, Carreon DC, Baumeister SE, et al. Influence of contextual environment and community-based dental education on practice plans of graduating seniors. J Dent Educ 2007;71(3):403-18.

23. Mofidi M, Gambrell A. Community-based dental partnerships: improving access to dental care for persons living with HIV/AIDS. J Dent Educ 2009;73(11):1247-59.

24. DeCastro JE, Matheson PB, Panagakos FS, et al. Alumni perspectives on community-based and traditional curricula. J Dent Educ 2003;67(4):418-26.

25. Piskorowski WA, Fitzgerald M, Mastey J, Krell R. Development of a sustainable community-based dental education program. J Dent Educ 2011;75(8):1038-43.

26. Bailit HL, McGowan TL. Assessing the impact of community-based education on dental school finances: introduction to the report. J Dent Educ 2011;75(10 Suppl):S5-S7.

27. Woolfolk MW, Price SS. Dental education: evolving student trends. J Dent Educ 2012;76(1):51-64.

28. Sheehan KB. Email survey response rates: a review. J Comput Mediated Commun 2006;6(2):1-38.

29. Hardigan PC, Succar CT, Fleisher JM. An analysis of response rate and economic costs between mail and webbased surveys among practicing dentists: a randomized trial. J Comm Health 2012;37(2):383-94. 